\title{
Formation of Transfer Products from Soybean Arabinogalactan and Glycerol by Galactanase from Penicillium citrinum
}

\author{
Hirofumi Nakano, Shigeyuki Takenishi and Yasuto Watanabe \\ Osaka Municipal Technical Research Institute, \\ 6-50 Morinomiya, l-chome, Joto-ku, \\ Osaka 536, Japan
}

Received December 28, 1987

\begin{abstract}
Formation of transfer products from soybean arabinogalactan and glycerol by endo-1,4- $\beta$-Dgalactanase from Penicillium citrinum was described. The amount of transfer products depended on the glycerol concentration. About $50 \%$ of the galactose residues which could be liberated from the polysaccharide by the enzyme were transferred to glycerol at an acceptor concentration of $2.5 \%$ $(\mathrm{w} / \mathrm{v})$. Transfer products with various polymerization degrees were accumulated at the beginning of the reaction and then those with higher polymerization degrees were degraded gradually. At a final stage of the reaction, two transfer products in addition to two hydrolysis products (galactose and galactobiose) were mainly accumulated. The two transfer products were isolated and their structures were examined. They were $2-O-\beta$-D-galactosyl glycerol and $O$ - $\beta$-D-galactosyl-( $(1 \rightarrow 4)-O-\beta$ D-galactosyl- $(1 \rightarrow 2)$ glycerol.
\end{abstract}

Some endo-glycanases (endo-type polysaccharide hydrolases) catalyze transfer reactions, ${ }^{1} \sim 4$ ) but such activities of glycanase are not so commonly observed, so there is less information than that on glycosidases, e.g., $\beta$ galactosidases. ${ }^{5 \sim 7)}$

In our previous papers, ${ }^{8,9)}$ the transfer reaction of endo-1,4- $\beta$-D-galactanase (EC 3.2.1.89) from Penicillium citrinum was reported: when $o$-nitrophenyl- $\beta$-D-galactoside (ONPG) was used as substrate, the galactoside acted as a donor and also as an acceptor to form oligosaccharides. The rapid liberation of $o$-nitrophenol (ONP) after a lag phase was estimated as the results of the formation of such transfer products and of their successive hydrolysis because these products were better substrates than the starting galactoside for the enzyme.

The acceptor specificity of the galactanase was also examined using soybean arabino- galactan (SAG) as a donor.9) The enzyme had broad specificity towards various alcohols, sugar alcohols, saccharides, and catechol.

This paper deals with some details of the formation of transfer products from SAG and glycerol by $P$. citrinum galactanase because glycerol was an efficient acceptor among those tested.

\section{MATERIALS AND METHODS}

Enzymes. Purified galactanase I was obtained from water extracts of a wheat bran culture of $P$. citrinum as described in our previous paper. ${ }^{10)}$ One unit of the enzyme liberates $1 \mu \mathrm{mol}$ of reducing sugar from SAG per min under our assay conditions. $\beta$-Galactosidase from the same origin was also purified as described before. ${ }^{11} \beta$ Galactosidase from E. coli (Grade IX) was purchased from the Sigma Chemical Co. Enzyme activities of these enzymes were assayed as described before. ${ }^{12)}$

Substrates. SAG was prepared by the procedure of Emi et al. ${ }^{13)} \mathrm{ONPG}$ was purchased from Nakarai Chemi-

Abbreviations: SAG, soybean arabinogalactan; ONPG, $o$-nitrophenyl- $\beta$-D-galactopyranoside; ONP, $o$-nitrophenol; TLC, thin layer chromatography; HPLC, high performance liquid chromatography; NMR, nuclear magnetic resonance; $\mathrm{Gal}_{2}, \beta$-1,4-galactobiose; 2-MG, glyceryl galactoside formed by $P$. citrinum galactanase; 2-DG, glyceryl galactobioside formed by $P$. citrinum galactanase; 1-MG, glyceryl galactoside formed by $E$. coli $\beta$-galactosidase. 
cals Co.

Aniline treatment. Reducing sugars were converted to their aniline derivatives with aniline acetate at $80^{\circ} \mathrm{C}$ for $3 \mathrm{hr}$ by the method of Hwang et al. ${ }^{14)}$ The aniline derivatives showed higher $R f$ values than the original sugars on a thin layer chromatogram. Transfer products which were nonreducing sugars were not affected by the treatment.

Thin layer chromatography. Thin layer chromatography (TLC) was done by the multiple ascending method using a silica gel plate (Kiesel Gel 60, Merck) and ethylacetateacetic acid-water $(3: 1: 1, \mathrm{v} / \mathrm{v})$ as a solvent. Sugars were detected by heating at $110^{\circ} \mathrm{C}$ for $10 \sim 20 \mathrm{~min}$ after spraying with $\mathrm{H}_{2} \mathrm{SO}_{4}-$ methanol $(1: 1, \mathrm{v} / \mathrm{v})$.

High performance liquid chromatography. Transfer products were measured by high performance liquid chromatography (HPLC) under the following conditions: column, Polygosil 60-10NH2 (Chemco Scientific Co., $4 \times$ $300 \mathrm{~mm})$; solvent, water-acetonitrile $(28: 72, \mathrm{v} / \mathrm{v})$; flow rate, $2.0 \mathrm{ml} / \mathrm{min}$; pump, Hitachi $635 \mathrm{~A}$; and detector, Shodex RI SEl1 refractometer.

${ }^{13} \mathrm{C}$-Nuclear magnetic resonance spectroscopy. ${ }^{13} \mathrm{C}$ Nuclear magnetic resonance $\left({ }^{13} \mathrm{C}-\mathrm{NMR}\right)$ spectra of $\mathrm{D}_{2} \mathrm{O}$ solutions of the samples were recorded at $22.5 \mathrm{MHz}$ with a Fourier transform NMR spectrometer FX90Q (JEOL Ltd.). The chemical shifts $(\delta)$ were given in ppm values with acetone $(\delta 31.4)$ as an internal standard.

Measurement of sugars and glycerol. Reducing sugars and total sugars were measured by the Somogyi-Nelson method $^{15,16)}$ and by the phenol-sulfuric acid method, ${ }^{17}$ respectively, using galactose as a standard. For the enzymatic measurements of galactose and glycerol, a "Test Combination Galactose UV Method" kit and a "Test Combination Glycerol UV Method" kit purchased from Boehringer Mannheim GmbH were used, respectively.

Isolation of the transfer products from $S A G$ and glycerol by galactanase. A reaction mixture containing $\mathrm{SAG}(0.8 \mathrm{~g})$, glycerol $(5 \mathrm{~g})$ and purified galactanase I (20 units) in $100 \mathrm{ml}$ of $50 \mathrm{~mm}$ acetate buffer $\left(\mathrm{pH} \mathrm{4.5)}\right.$ was incubated at $40^{\circ} \mathrm{C}$ for $48 \mathrm{hr}$. The remained polysaccharide was removed by the addition of $200 \mathrm{ml}$ of ethanol to the mixture. After the removal of ethanol by evaporation, the solution was then treated with aniline acetate at $80^{\circ} \mathrm{C}$ for $3 \mathrm{hr}$. After the removal of colored substances by extraction with ethyl ether and of the remaining solvent by evaporation, the solution was put on a column $(3 \times 32 \mathrm{~cm})$ of activated carbon. After the column had been washed with water (about $1.5 \mathrm{l}$ ), transfer products were eluted with a linear gradient of ethanol concentration prepared from $1 \mathrm{l}$ each of water and $35 \%(\mathrm{v} / \mathrm{v})$ of ethanol at a flow rate of $30 \mathrm{ml} / \mathrm{hr}$. Two peaks of sugars were collected separately, evaporated, and further purified by passing through a column $(2 \times 48 \mathrm{~cm})$ of Bio-Gel P-2 equilibrated with water. Two preparations, called 2-MG and 2-DG in this study, were obtained. 2-MG (155 mg) was homogeneous by TLC and HPLC. From the preparation of 2-DG, an unidentified saccharide (less than $5 \%$ of $2-\mathrm{DG}$ ) which contained galactose and arabinose as components was removed by HPLC. 2-DG (93 mg) thus obtained was used in this study.

Preparation of a transfer product from $O N P G$ and glycerol by $E$. coli $\beta$-galactosidase. As a reference compound, the transfer product formed from ONPG and glycerol by $E$. coli $\beta$-galactosidase was also prepared.

The reaction mixture $(200 \mathrm{ml})$ contained $O N P G$ $(0.602 \mathrm{~g})$, glycerol $(6 \mathrm{~g})$, and the enzyme ( 124 units) in $50 \mathrm{~mm}$ phosphate buffer ( $\mathrm{pH} 7.3$ ) containing $1 \mathrm{~mm} \mathrm{MgCl}_{2}$. After incubation at $40^{\circ} \mathrm{C}$ for $30 \mathrm{~min}$, the enzyme was inactivated by boiling for $10 \mathrm{~min}$. The mixture was then treated with aniline acetate at $80^{\circ} \mathrm{C}$ for $3 \mathrm{hr}$. ONP and colored substances were removed by extraction with ethyl ether. A saccharide, tentatively named 1-MG in this study, was isolated by activated carbon column chromatography and Bio-Gel P-2 column chromatography. 1-MG (502 mg) gave a single spot and a single peak by TLC and HPLC, respectively.

Measuring the amounts of the part of $S A G$ susceptible to hydrolysis by galactanase. Because the final hydrolysis products of SAG by galactanase alone were galactose and several galactooligosaccharides, ${ }^{10}$ the part of SAG susceptible to hydrolysis by galactanase (maybe most of the galactan part of the polysaccharide ${ }^{183}$ ) was measured in the presence of $\beta$-galactosidase to digest these oligosaccharides to galactose. ${ }^{12}$ ) The amount of SAG used was corrected for its moisture content $(10.2 \%)$. The reaction mixture $(4.0 \mathrm{ml})$ containing SAG $(81.4 \mathrm{mg}$ as dry weight $/ \mathrm{ml})$, galactanase $(4.0 \mathrm{unit} / \mathrm{ml})$ and $\beta$-galactosidase $(10 \mathrm{unit} / \mathrm{ml})$ from $P$. citrinum in $50 \mathrm{~mm}$ acetate buffer $(\mathrm{pH}$ 4.5) was incubated at $40^{\circ} \mathrm{C}$ for $20 \mathrm{hr}$. The completion of the hydrolysis by the two enzymes was confirmed by TLC, and $41.4 \mathrm{mg}$ of galactose was detected in the mixture. Since the $\beta$-galactosidase from $P$. citrinum did not act on SAG ${ }^{11}$ the enzymatically susceptible part in the polysaccharide was estimated to be $50.9 \%$ of its dry weight.

Calculation of transfer ratio. Galactose residues used for the formation of transfer products (A) were calculated from the total amounts of 2-MG and 2-DG measured by HPLC. Galactose residues in the enzymatically susceptible part in SAG (B) were calculated as $50.9 \%$ of the dry weight of $\mathrm{SAG}$ used. The transfer ratio was defined as $(\mathrm{A} / \mathrm{B}) \times 100(\%)$.

Chemicals. Other chemicals used were of the highest grade commercially available. 


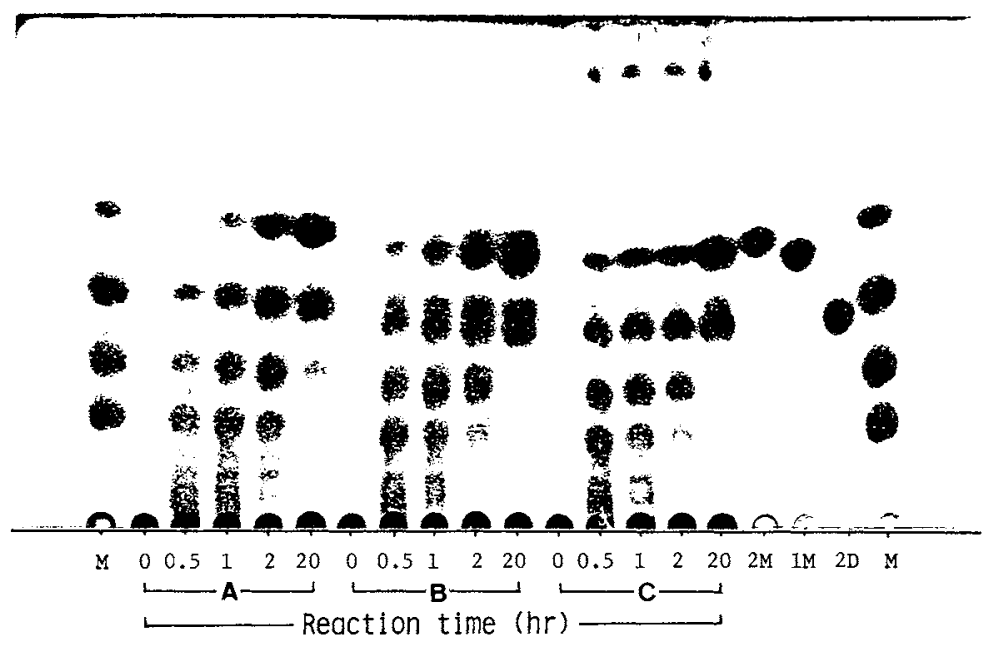

FIG. 1. Thin Layer Chromatogram of the Reaction Products from SAG and Glycerol by Galactanase. Reaction mixtures $(4.0 \mathrm{ml})$ containing SAG $(102 \mathrm{mg} / \mathrm{ml})$, glycerol $(25 \mathrm{mg} / \mathrm{ml})$, and galactanase I $(0.313$ unit $/ \mathrm{ml}$ ) in $50 \mathrm{~mm}$ acetate buffer ( $\mathrm{pH} \mathrm{4.5)}$ were incubated at $40^{\circ} \mathrm{C}$. In a control experiment (A) glycerol was omitted from the mixture. At intervals, the reaction was stopped by boiling and analyzed by TLC directly (B) or after aniline treatment (C). M, galactose-galactotetraose; 2M, 2-MG; IM, I-MG; 2D, 2-DG.

\section{RESULTS}

\section{Course of the transfer reaction}

The reaction products formed in the presence of glycerol were analyzed by TLC (Fig. 1). The transfer products could be discriminated from the hydrolysis products by their slight lower $R f$ values or by the spots after aniline treatment. ${ }^{14}$ ) At the beginning of the reaction, several transfer products with different degrees of polymerization were formed. On longer incubation, the transfer products with higher degrees of polymerization disappeared and four main products, two hydrolysis products (galactose and $\mathrm{Gal}_{2}$ ) and two transfer products, accumulated. In this study, these transfer products were referred to as $2-\mathrm{MG}$ and 2-DG in the order of the mobility on the chromatogram.

Figure 2 shows the progressive release of reducing sugars. The liberation of reducing sugars was greatly suppressed by the addition of glycerol to the reaction mixture. Large differences in the reducing sugars were considered to depend on the amounts of the transfer products formed. The differences, however, might not correspond to the amounts of the transfer

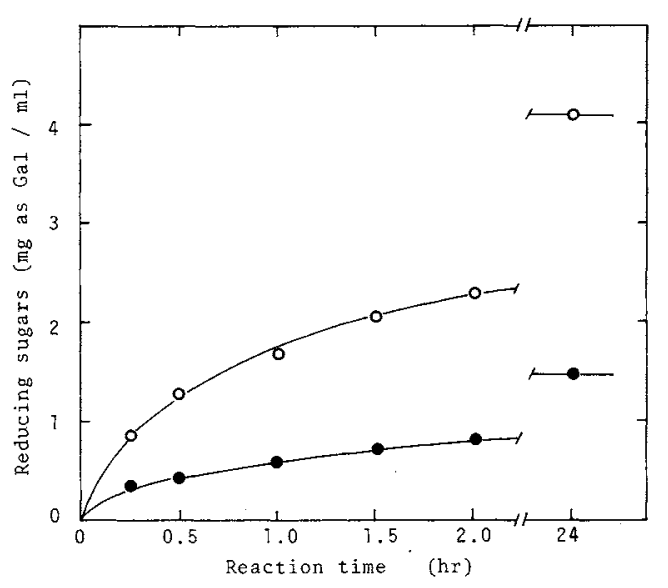

FIG. 2. Progressive Liberation of Reducing Sugars from $\mathrm{SAG}$ in the Presence and Absence of Glycerol by Galactanase.

Reaction conditions were the same as in the legend of Fig. 1. (O-O), control (without glycerol); ( -0$)$, glycerol $(25 \mathrm{mg} / \mathrm{ml})$.

products directly, because reducing sugars other than galactose were also formed as hydrolysis products by the enzyme.

Effects of SAG concentrations on the formation of transfer products

The amounts of 2-MG and 2-DG which 


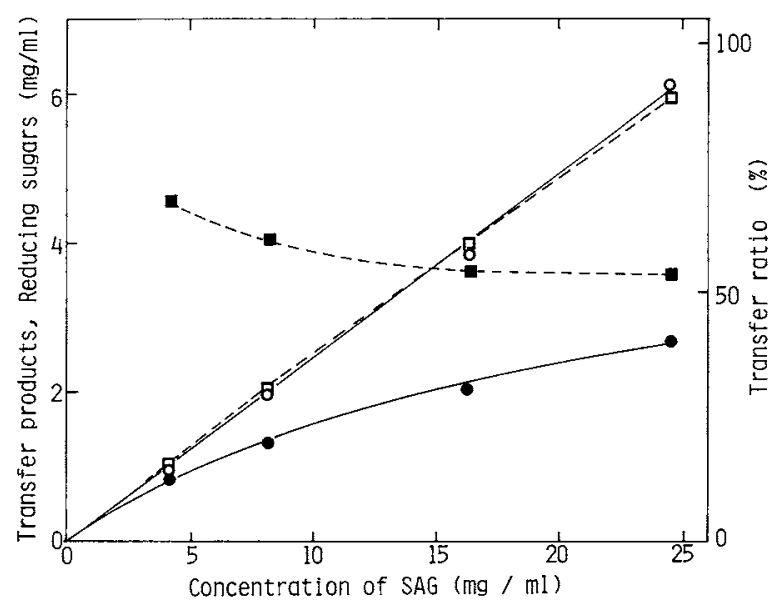

FIG. 3. Effects of SAG Concentrations on the Formation of Transfer Products.

Reaction mixture $(4.0 \mathrm{ml})$ containing glycerol $(50 \mathrm{mg} / \mathrm{ml})$, galactanase I $(1.0 \mathrm{unit} / \mathrm{ml})$, and various concentrations of SAG $(4 \sim 25 \mathrm{mg} / \mathrm{ml})$ in $50 \mathrm{~mm}$ acetate buffer $(\mathrm{pH} 4.5)$ was incubated at $40^{\circ} \mathrm{C}$ for $20 \mathrm{hr}$. After the reaction was stopped by boiling, the mixture was treated with aniline acetate at $80^{\circ} \mathrm{C}$ for $3 \mathrm{hr}$. The completion of the treatment was confirmed by the disappearance of the spots corresponding to hydrolysis products on a thin layer chromatogram. The solution was then put on an activated carbon column $(2.1 \times 9.5 \mathrm{~cm})$ to separate the transfer products from aniline-derivatives of hydrolysis products. After the column was washed with water, the eluate (about $100 \mathrm{ml}$ ) with $30 \%(\mathrm{v} / \mathrm{v})$ ethanol was collected, evaporated, and filtered through membrane filter $(0.45 \mu \mathrm{m}$, Millipore Co.). The transfer products were measured by HPLC. The transfer ratio was calculated as described in Materiais AND Methods. (O-O), 2-MG $(\mathrm{mg} / \mathrm{ml}) ;(-\infty), 2-\mathrm{DG}(\mathrm{mg} / \mathrm{ml})$; ( $\square$--- $\mathbf{\square})$, transfer ratio $(\%) ;(\square--\square)$, the difference of reducing sugars formed in the presence and absence of glycerol ( $\mathrm{mg}$ as galactose $/ \mathrm{ml}$ ).

accumulated at various SAG concentrations were measured by HPLC. Because 2-MG could not be completely separated from galactose or 2-DG from $\mathrm{Gal}_{2}$ on HPLC, the reducing sugars were first removed from the mixtures by aniline treatment then carbon column chromatography. The transfer ratio (galactose residues in 2-MG and 2-DG/galactose residues in the part of SAG susceptible to hydrolysis by galactanase) was used to characterize the extent of the transfer reaction. Figure 3 shows the results after $20 \mathrm{hr}$ of reaction. The formation of 2-MG and 2-DG increased with the SAG concentration and the transfer ratio was almost constant $(50 \sim 60 \%)$. The slight decrease in the transfer ratio at high SAG concentrations might be due to the small amounts of highly polymerized products. These were not measured by HPLC because they were only detectable as tailing parts appearing after the peak of 2-DG.
Effects of glycerol concentrations on the formation of transfer products

The effects of glycerol concentrations $(0 \sim 10 \%)$ on the formation of the transfer products were studied (Fig. 4). The transfer ratio increased with the increase of the acceptor concentration and about half of galactose residues in the enzymatically susceptible part in SAG were transferred at a glycerol concentration of $2.5 \%$.

2-DG was formed better than 2-MG at high glycerol concentrations. Because each mixture was incubated for the same reaction time $(20 \mathrm{hr})$, part of the 2-DG which was formed at low glycerol concentrations might be degraded further by the enzyme.

\section{Isolation of transfer products}

To elucidate the structures of the transfer products, 2-MG and 2-DG were isolated as described in MATERIALS AND METHODS. The aniline derivatives of the hydrolysis products were 
adsorbed onto the activated carbon column more strongly than the transfer products and were still retained in the column after the elution of the transfer products. 2-MG and 2DG were eluted separately with a linear gradient of ethanol concentration $(0 \sim 30 \%)$. A transfer product formed from ONPG and

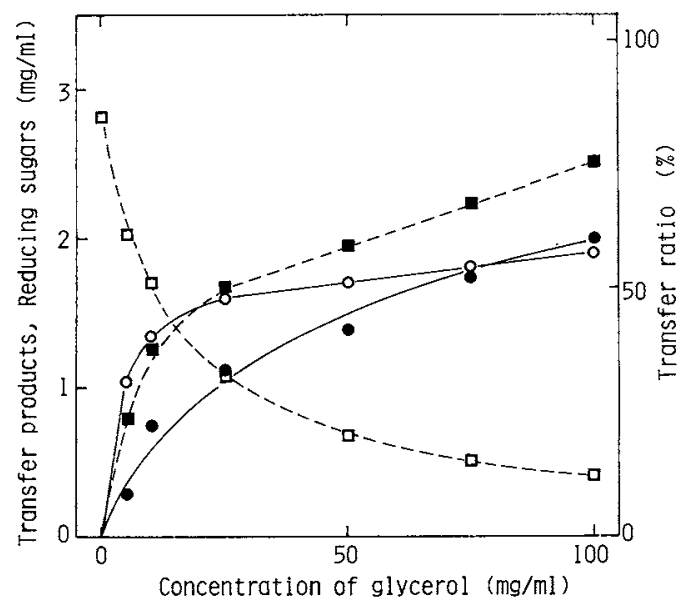

FIG. 4. Effects of Glycerol Concentrations on the Formation of Transfer Products.

Reaction mixtures $(4.0 \mathrm{ml})$ containing SAG $(8.14 \mathrm{mg} / \mathrm{ml})$, galactanase I (1.0 unit $/ \mathrm{ml}$ ), and various concentrations of glycerol $(0 \sim 100 \mathrm{mg} / \mathrm{ml})$ in $50 \mathrm{~mm}$ acetate buffer $(\mathrm{pH} 4.5)$ were incubated at $40^{\circ} \mathrm{C}$ for $20 \mathrm{hr}$. The transfer products in the mixtures were measured as described in the legend of Fig. 3. (O-O), 2-MG $(\mathrm{mg} / \mathrm{ml})$; ( - $)$, 2-DG $(\mathrm{mg} / \mathrm{ml})$; (ם--- $\square$ ), transfer ratio $(\%) ;(\square--\square)$, reducing sugars (mg as galactose $/ \mathrm{ml}$ ). glycerol by $E$. coli $\beta$-galactosidase was also obtained by almost the same procedures and referred as $1-\mathrm{MG}$ in this study.

These three glyceryl galactosides appeared to be homogeneous by TLC and HPLC. 2MG showed a slightly larger mobility than 1$M G$ on the thin layer chromatogram but had the same retention time as $1-M G$ by HPLC.

\section{Structures of transfer products}

The structures of 2-MG and 2-DG were studied and compared with that of $1-\mathrm{MG}$ which was considered to be $1-O-\beta$-D-galactosyl$\mathrm{D}($ or $\mathrm{L}$ )-glycerol (the main product was reported to be a D-glycerol stereoisomer). ${ }^{19)}$

2-MG and 2-DG were incubated with $\beta$ galactosidases from $P$. citrinum and $E$. coli (Table I). 2-MG was hydrolyzed by the two enzymes almost completely to form galactose and glycerol in an almost equimolar ratio, indicating the saccharide was glyceryl galactoside bound with a $\beta$-galactosidic linkage.

2-DG was not hydrolyzed by the $E$. coli enzyme, but could be by the enzyme from the mold. The galactose/glycerol ratio measured after complete hydrolysis was almost two, indicating that 2-DG consisted of two galactose residues and one glycerol moiety bound with $\beta$-galactosidic linkages.

The two $\beta$-galactosidases liberated galactose from $2-\mathrm{MG}$ and $1-\mathrm{MG}$ at different rates. These

TABle I. Hydrolysis of 2-MG, 1-MG, AND 2-MG By $\beta$-Galactosidases From $P$. citrinum and $E$. coli

A reaction mixture $(4.0 \mathrm{ml})$ containing substrate $(1.0 \mathrm{~mm})$ and the enzyme $(0.25 \mathrm{unit} / \mathrm{ml})$ was incubated at $40^{\circ} \mathrm{C}$ for various times. Galactose and glycerol liberated in the mixture were measured enzymatically. Buffers used were $50 \mathrm{~mm}$ acetate $(\mathrm{pH} 4.5)$ and $50 \mathrm{~mm}$ phosphate $\left(\mathrm{pH} \mathrm{7.3)} \mathrm{containing} 1 \mathrm{mM} \mathrm{MgCl}_{2}\right.$ for $P$. citrinum and $E$. coli enzymes, respectively.

\begin{tabular}{|c|c|c|c|c|}
\hline Substrate & $\begin{array}{c}\text { Enzyme }^{a} \\
\text { origin }\end{array}$ & $\begin{array}{l}\text { Initial }^{b} \\
\text { velocity }\end{array}$ & $\begin{array}{l}\text { Hydrolysis } \\
\text { degree }(\%)\end{array}$ & $\frac{\text { Galactose }}{\text { Glycerol }}$ \\
\hline \multirow[t]{2}{*}{ 2-MG } & $\mathrm{P}$ & 0.0228 & 99.4 & 1.03 \\
\hline & $\mathrm{E}$ & 0.0156 & 100 & 1.02 \\
\hline \multirow[t]{2}{*}{$1-\mathrm{MG}$} & $\mathrm{P}$ & 0.0095 & 100 & 1.02 \\
\hline & $\mathrm{E}$ & 0.0434 & 100 & 1.00 \\
\hline \multirow[t]{2}{*}{ 2-DG } & $\mathrm{P}$ & 0.0233 & 97.5 & 1.92 \\
\hline & $E$ & 0 & 0 & - \\
\hline
\end{tabular}

a P, P. citrinum; E, E. coli.

b $\mu$ mol of galactose liberated per $\mathrm{ml}$ per min at the enzyme concentration of $0.25 \mathrm{unit} / \mathrm{ml}$.

c The values were calculated from the amounts of galactose liberated after 20 hr of incubation. 
Table II. ${ }^{13} \mathrm{C}$ Chemical Shifts of Transfer Products and Related Compounds in $\mathrm{D}_{2} \mathrm{O}$

Data of floridoside, D- and L-forms of isofloridoside were taken from reference 20. Chemical shifts were expressed based on that of the internal acetone $(\delta 31.4 \mathrm{ppm})$.

\begin{tabular}{|c|c|c|c|c|c|c|c|c|c|}
\hline \multirow{3}{*}{ Compound } & \multicolumn{9}{|c|}{$\delta$ in ppm } \\
\hline & \multicolumn{6}{|c|}{ Galactose residue } & \multicolumn{3}{|c|}{ Glycerol residue } \\
\hline & C-1 & $\mathrm{C}-2$ & $\mathrm{C}-3$ & C-4 & $\mathrm{C}-5$ & C-6 & $\mathrm{C}-1^{\prime}$ & $\mathrm{C}-2^{\prime}$ & $\mathrm{C}-3^{\prime}$ \\
\hline 2-MG & 103.6 & 72.1 & 73.8 & 69.8 & 76.3 & $62.1^{a}$ & $62.2^{a}$ & 82.1 & $62.7^{a}$ \\
\hline $1-\mathrm{MG}$ & 104.1 & $71.8^{a}$ & 73.8 & 69.7 & 76.2 & 62.1 & $71.8^{a}$ & $71.5^{a}$ & 63.5 \\
\hline Glycerol & & & & & & & $63.6^{a}$ & 73.2 & $63.6^{a}$ \\
\hline $\mathrm{Me}-\beta-\mathrm{Gal}^{b}$ & 104.9 & 71.8 & 73.9 & 69.8 & 76.2 & 62.1 & \multicolumn{2}{|c|}{$58.2(\mathrm{OMe})^{f}$} & \\
\hline Flo. & 99.2 & 69.6 & 70.5 & 70.4 & 72.2 & 62.3 & 62.5 & 79.9 & 61.5 \\
\hline D-Isoflo. ${ }^{d}$ & 99.9 & 69.6 & 70.6 & 70.4 & 72.1 & 62.3 & 71.8 & 70.1 & 63.7 \\
\hline L-Isoflo. ${ }^{e}$ & 99.6 & 69.8 & 70.6 & 70.4 & 72.1 & 62.3 & 71.6 & 69.8 & 63.8 \\
\hline \multicolumn{10}{|c|}{ a Assignments may be interchangeable. } \\
\hline \multicolumn{10}{|c|}{ b $O$-methyl $\beta$-D-galactoside. } \\
\hline \multicolumn{10}{|c|}{ c Floridoside. } \\
\hline \multicolumn{10}{|c|}{${ }^{d}$ Isofloridoside (D-glycerol isomer). } \\
\hline \multicolumn{10}{|c|}{$e \quad$ Isofloridoside (L-glycerol isomer). } \\
\hline \multicolumn{10}{|c|}{$f$ Carbon in methyl group. } \\
\hline
\end{tabular}

results together with the different mobility on the thin layer chromatogram suggested a structural difference between the two galactosides.

Then ${ }^{13} \mathrm{C}$-NMR was used for the further elucidation. In Table II, the chemical shifts and the assignments of 2-MG, 1-MG and their related compounds are given.

In the spectrum of 2-MG, three hydroxy methylene carbon signals appeared at 62.1, 62.2 , and $62.7 \mathrm{ppm}$. This indicated that both hydroxymethyl groups in the glycerol moiety must be unsubstituted, i.e. the linkage occurred at C-2' (82.1 ppm). On the other hand, only two hydroxy methylene carbon signals (at 62.1 and $63.5 \mathrm{ppm}$ ) were observed in the spectrum of $1-\mathrm{MG}$ in which a galactose residue was expected to be bound with the $\mathrm{C}-\mathrm{1}^{\prime}$ of glycerol moiety. Compared to glycerol, the downfield shift for $\mathrm{C}^{-2} 2^{\prime}$ in $2-\mathrm{MG}(8.9 \mathrm{ppm})$ also support the occurrence of the linkage at this carbon. Similar differences in the spectra of 2-MG and $1-\mathrm{MG}$ were also reported in those of floridoside (2-O- $\alpha$-D-galactosyl glycerol) and isofloridoside (1-O- $\alpha$-D-galactosyl-D-glycerol or 1-O- $\alpha-\mathrm{D}$-galactosyl-L-glycerol). ${ }^{20)}$

2-DG was hydrolyzed by trifluoroacetic acid (TFA) at $100^{\circ} \mathrm{C}$ for various times (Fig. 5A).
The saccharide was also hydrolyzed by the galactanase (Fig. 5B). The appearance of $\mathrm{Gal}_{2}$ and 2-MG and disappearance of 1-MG in the partial acid and enzymatic hydrolyzates suggested that 2 -DG was $O$ - $\beta$-galactosyl- $(1 \rightarrow 4)$ $O$ - $\beta$-D-galactosyl-( $1 \rightarrow 2)$-glycerol.

\section{Hydrolysis of transfer products by galactanase}

The susceptibility of 2-MG, 1-MG, and 2DG to hydrolysis by galactanase were examined (Fig. 6). From 2-MG and 1-MG, no detectable amount of glycerol was liberated, even at a high enzyme concentration (25 unit $/ \mathrm{ml}$ ) and after a long incubation time $(24 \mathrm{hr})$. Upon the addition of $\beta$-1,4-linked galactotriose $\left(\mathrm{Gal}_{3}\right)$, however, the liberation of glycerol occurred and the liberation rate from 2-MG was much faster than that of 1-MG (Fig. 6A).

2-DG was hydrolyzed by the enzyme to form galactose and glycerol (Fig. 6B). The formation of galactose, 2-MG, and $\mathrm{Gal}_{2}$ were observed by TLC during the hydrolysis (Fig. $5 \mathrm{~B})$. This indicated that the enzyme hydrolyzed not only the linkage between the two tandemly-linked galactose residues but also that between the galactose and glycerol res- 
A
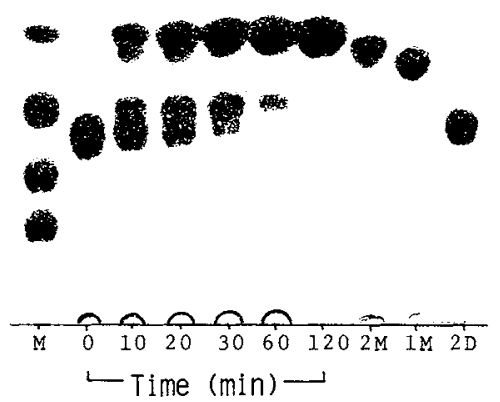

B

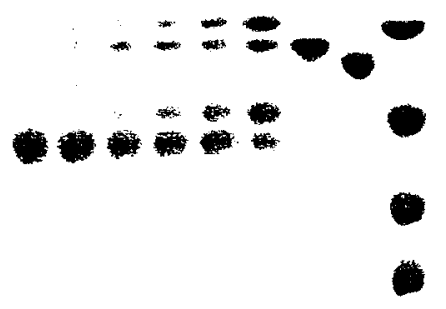

P
L Time $(\mathrm{min}) \longrightarrow$

FIG. 5. Thin Layer Chromatogram of the Hydrolyzates of 2-DG by Trifluoroacetic Acid and by Galactanase.

2-DG ( $1 \mathrm{mM})$ was hydrolyzed with $1 \mathrm{~N}$ TFA at $100^{\circ} \mathrm{C}$ for various times. After the removal of TFA by evaporation, the hydrolyzate was analyzed by TLC (A). The reaction mixtures, containing 2-DG ( $5 \mathrm{mM}$ ) and galactanase ( $4 \mathrm{unit} / \mathrm{ml}$ ) in $50 \mathrm{~mm}$ acetate buffer (pH 4.5), were incubated at $40^{\circ} \mathrm{C}$. At intervals, $20 \mu \mathrm{l}$ of the mixture was spotted on TLC plate and analyzed (B). M, galactose-galactotetraose; 2M, 2-MG; 1M, 1-MG; 2D, 2-DG.

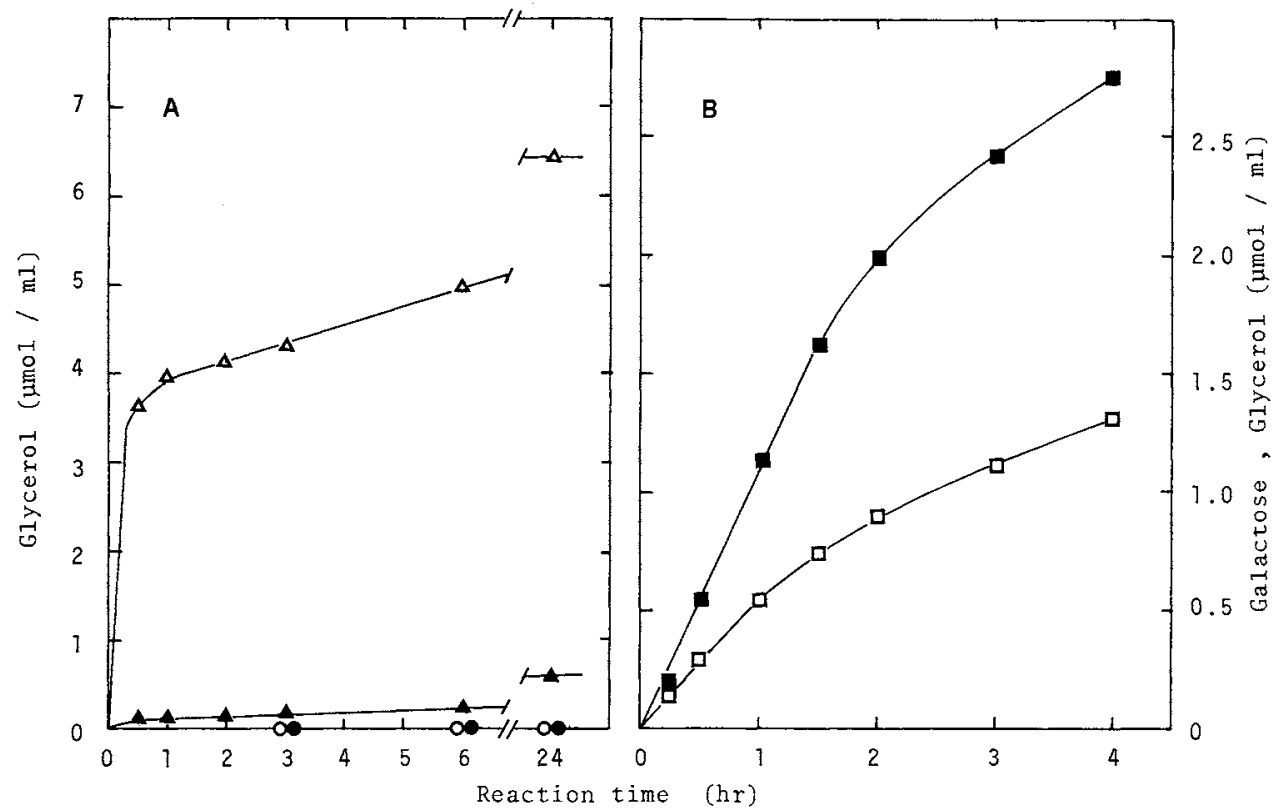

Fig. 6. Courses of Hydrolysis of the Transfer Products by Galactanase.

Hydrolysis of 2-MG and 1-MG were examined by the liberation of glycerol in the absence and the presence of $\mathrm{Gal}_{3}$ (A). Hydrolysis of 2-DG was monitored by the liberation of galactose and glycerol (B). For 2-MG and 1$\mathrm{MG}$, the substrates $(25 \mathrm{~mm})$ and the galactanase $(25 \mathrm{unit} / \mathrm{ml})$ were incubated at $\mathrm{pH} 4.5$ and $40^{\circ} \mathrm{C} . \mathrm{Gal}_{3}$ was used at a concentration of $4.73 \mathrm{~mm}$. For 2-DG, the substrate $(5.0 \mathrm{~mm})$ and the enzyme $(4 \mathrm{unit} / \mathrm{ml})$ were incubated under the same conditions. At various times, reaction was stopped by adding $2 \mathrm{~N} \mathrm{HCl}(10 \mu 1)$ to the mixture $(0.5 \mathrm{ml})$ and glycerol or galactose liberated in the mixture was measured enzymatically. $(\mathrm{O}-\mathrm{O}), 2$ $\mathrm{MG} ;(\triangle-\triangle), 2-\mathrm{MG}+\mathrm{Gal}_{3} ;(\bullet-\bullet), 1-\mathrm{MG} ;(\mathbf{\Delta - \Delta}), 1-\mathrm{MG}+\mathrm{Gal}_{3} ;(\mathbf{\square}-\mathbf{0})$, the liberation of galactose from 2-DG; $(\square-\square)$, the liberation of glycerol from 2-DG. 
idues in 2-DG molecule.

\section{DISCUSSION}

The ability of glycerol to act as an acceptor in the enzymatic transglycosylation reactions has been reported several times. It was reported that Candida $\alpha$-glucosidase formed a mixture of 1-O- $\alpha$-D-glucosyl-D-glycerol, 1-O- $\alpha$. D-glucosyl-L-glycerol, and trances of glyceryl glucobioside and glyceryl glucotrioside. ${ }^{21}$ $\beta$-Glucosidase ${ }^{22)}$ and $N$-acetyl- $\beta$-D-glucosaminidase $^{23)}$ also gave transfer products from glycerol and their respective substrates. $\beta$ Galactosidase from $E$. coli, the most characterized enzyme in regards to the transgalactosylation reaction, was reported to form 1$O-\beta$-D-galactosyl-D-glycerol as a main product. ${ }^{5)}$ The enzymes studied in these cases, however, were glycosidases which hydrolyze their substrates exo-wise.

As reported in this and previous papers, ${ }^{9)}$ we studied the transfer reaction catalyzed by the endo-1,4- $\beta$-D-galactanase from $P$. citrinum using SAG, the natural polymeric substrate for the enzyme, as a donor, and glycerol as an acceptor and observed some differences from the transfer reaction catalyzed by $\beta$-galactosidase.

One of the differences is in the degree of polymerization of the products. During the course of the galactanase-catalyzed reaction, several transfer products including 2-MG and 2-DG accumulated and then products with higher degrees of polymerization disappeared gradually. At an initial stage of the reaction, the galactanase, an endo-type enzyme, might transfer galactooligosyl units with various polymerization degrees to glycerol.

On the other hand, in the transgalactosylation reaction catalyzed by $\beta$-galactosidases, one galactosyl residue is transferred to the acceptor molecule in each step. Therefore, $\beta$ galactosidases could not form such high molecular weight transfer products. In fact, $E$. coli $\beta$-galactosidase did not give such products in considerable amounts in our experiment. The same observation also appeared in some other reports. ${ }^{5,24)}$

Disappearance of the saccharides with high polymerization degrees on prolonged incubation suggested that some part of $2-\mathrm{MG}$ and 2-DG might be also formed as secondary products from these high molecular weight saccharides.

The difference in the positions of linkages in the two glyceryl galactosides, one formed by the galactanase and the other by $E$. coli $\beta$ galactosidase, is another interesting point. When the galactanase was used, the linkage between galactose residue(s) and glycerol occurred at the $\mathrm{C}-2$ ' position of glycerol moiety almost exclusively. On the contrary, the linkage was formed at $\mathrm{C}$ - $1^{\prime}$ when $\beta$-galactosidase from $E$. coli was used.

This difference might be reasonably understood by analogizing as follows. It is known that galactosyl transfer catalyzed by $E$. coli $\beta$ galactosidase occurs preferably to primary hydroxyl groups. When hexoses are used as acceptors, the main transfer products are $\beta$ 1,6-linked disaccharides (the order for the formation is $(1 \rightarrow 6)>(1 \rightarrow 4)>(1 \rightarrow 3)) .{ }^{25)}$ As reported in our previous paper, ${ }^{8)}$ however, the galactanase formed predominantly a homogeneous series of $\beta$-1,4-linked saccharides in the reaction with ONPG. Likewise, the enzyme will give galactosides linked at $\mathrm{C}-2^{\prime}$ position, at secondary hydroxyl groups in the glycerol molecule.

So far, however, we could not find the relation between the specificity of the galactanase for acceptors and the structural features of the acceptor molecules. As reported previously, ${ }^{9)}$ ethanol and ethyleneglycol (1,2-ethanediol) which have only primary hydroxyl group(s) gave transfer products. 1-Propanol, 1,3-propandiol, and glycerol acted as acceptors but 2-propanol did not. 1-Butanol, 1,2-, 1,3-, 1,4-, 2,3-butandiols, and meso-erythritol gave transfer products but 2-butanol did not. Although the enzyme gave C-2' substituted glycerol almost exclusively, a secondary hydroxyl group seemed not to be essential. Furthermore, alcohols which have only one secondary hydroxyl group were inactive as 
acceptors. The location of hydroxyl group(s) in a certain acceptor molecule seemed to be more important than the difference in the class of hydroxyl groups.

The difference in the linked position in galactose residues with glycerol moieties was reflected in the hydrolysis rates by $\beta$-galactosidases. $P$. citrinum $\beta$-galactosidase ${ }^{11)}$ hydrolyzed 2-MG about twice as fast as 1-MG. On the contrary, E. coli enzyme degraded 1-MG about 3 times faster than 2-MG. This indicated the differences of the substrate specificity of the two enzymes. As reported in our previous paper, ${ }^{12)}$ the two $\beta$-galactosidases also showed large differences in the specificity towards a homogeneous series of galactooligosaccharides: $E$. coli enzyme could not hydrolyze any of these saccharides but $P$. citrinum enzyme hydrolyzed them.

Since the hydrolysis rates of the 1-MG and $2-\mathrm{MG}$ by the two $\beta$-galactosidases were found to be different, the difference in the transfer products from ONPG and glycerol were also compared by TLC. E. coli enzyme formed 1MG predominantly, but $P$. citrinum $\beta$-galactosidase formed a mixture of $1-\mathrm{MG}$ and $2-\mathrm{MG}$. The main product by the latter enzyme, however, was 1-MG (data not shown).

The degradation of 2-MG and 1-MG by the galactanase was examined by the liberation of glycerol. These galactosides could not be degraded under the reaction conditions used, but when $\mathrm{Gal}_{3}$ was added to the mixture, glycerol was liberated. As in the reaction of the enzyme with $\mathrm{ONPG},{ }^{8)} \mathrm{Gal}_{3}$ was considered to act as a donor to form transfer products with 2-MG and 1-MG. Glycerol was liberated from these transfer products because transfer products such as 2-DG were much better substrates than the starting glyceryl galactoside.

Furthermore, in the presence of $\mathrm{Gal}_{3}$, glycerol liberation rate from $2-\mathrm{MG}$ by the galactanase was much higher than that from 1-MG. There are several possibilities for the reason why I-MG showed such a low glycerol liberation rate: lower acceptor-efficiency of $1-\mathrm{MG}$ than $2-\mathrm{MG}$ in the transfer reaction, lower hydrolysis rate of transfer products derived from $\mathrm{Gal}_{3}$ and 1-MG, or both reasons. But it still remains to be seen.

Acknowledgment. We wish to thank Dr. Masaki Nakamura in this institute for his measuring the ${ }^{13} \mathrm{C}$ NMR spectra and useful discussions.

\section{REFERENCES}

1) D. M. Chipman, Biochemistry, 10, 1714 (1971).

2) H. Fujimori, M. Ohnishi, M. Sakoda, R. Matsuno and K. Hiromi, FEBS Lett., 72, 283 (1976).

3) J. D. Allen and J. A. Thoma, Biochemistry, 17, 2338 (1978).

4) P. Biely, M. Vrašanská and Z. Krátký, Eur. J. Biochem., 112, 375 (1980).

5) K. Wallenfels and R. Weil, "The Enzymes," Vol. 7, ed. by P. D. Boyer, Academic Press, New York, 1972, p. 617.

6) R. E. Huber, G. Kurz and K. Wallenfels, Biochemistry, 15, 1994 (1974).

7) R. E. Huber, M. T. Gaunt and K. L. Hurlburt, Arch. Biochem. Biophys., 234, 151 (1984).

8) H. Nakano, S. Takenishi and Y. Watanabe, Agric. Biol. Chem., 50, 3005 (1986).

9) H. Nakano, S. Takenishi and Y. Watanabe, Agric. Biol. Chem., 52, 1319 (1988).

10) H. Nakano, S. Takenishi and Y. Watanabe, Agric. Biol. Chem., 49, 3445 (1985).

11) Y. Watanabe, Y. Kibesaki, S. Takenishi, K. Sakai and Y. Tsujisaka, Agric. Biol. Chem., 43, 2267 (1979).

12) H. Nakano, S. Takenishi and Y. Watanabe, Agric. Biol. Chem., 51, 2267 (1987).

13) S. Emi, J. Fukumoto and T. Yamamoto, Agric. Biol. Chem., 35, 1891 (1971).

14) C.-J. Hwang, K. Suyama and S. Adachi, Nippon Nögeikagaku Kaishi, 61, 339 (1987).

15) N. Nelson, J. Biol. Chem., 153, 375 (1944).

16) M. Somogyi, J. Biol. Chem., 195, 19 (1952).

17) M. Dubois, K. A. Gilles, J. K. Hamilton, P. A. Robers and F. Smith, Anal. Chem., 28, 350 (1956).

18) J. M. Labavitch, L. E. Freeman and P. Albersheim, J. Biol. Chem., 251, 5904 (1976).

19) W. Boos, J. Lehman, and K. Wallenfels, Carbohydr. Res., 7, 381 (1968).

20) J. Meng, K.-G. Rosell and L. M. Srivastava, Carbohydr. Res., 161, 171 (1987).

21) T. Sawai and E. J. Hehre, J. Biol. Chem., 237, 2047 (1962).

22) M. A. Jermyn, Australian J. Biol. Sci., 11, 114 (1958).

.23) T. Mega, T. Ikenaka and Y. Matsushima, $J$. Biochem., 72, 1391 (1972).

24) C. Burstein, M. Cohn, A. Kepes and J. Monod, Biochim. Biophys. Acta, 95, 634 (1965).

25) K. Wallenfels and O. P. Malhotra, Adv. Carbohydr. Chem., 16, 239 (1961). 